\title{
Pecking Order in Physics Productivity
}

An analysis of the variations in productivity of physicists from one institution to another in the United States is one of the first by-products of the programme of research on physics information mounted in the past few years by the American Institute of Physics. If productivity is measured in the number of papers published in a particular period, the institute finds that in physics productivity, ten institutions are responsible for a quarter of all the papers published in a group of predominantly American journals representing 28 per cent of the whole of physics. Among university laboratories, ten institutions produced no less than a third of the papers published in the group of journals entered in the study.

The study now reported was based on the papers published in nine physics journals in a period of six months in 1966-67. The journals concerned are J. Appl. Phys., J. Chem. Phys., J. Opt. Soc. Amer., Nuclear Phys., Nuovo Cimento, Phys. Rev., Phys. Rev. Letters, Phys. of Fluids and Phys. Letters. These were selected from the thirty-eight journals maintained on the computer file at MIT as part of the technical information project. Two thirds of the papers appearing in the journals were American in origin-a ratio which must be compared with the 18 per cent contribution of American authors to what is believed to be the world-wide literature of physies. In the analysis, the organizations were counted by geographical location, the output from contract research centres was credited to the sponsoring authority, joint authorship was counted fractionally and incomplete entries were discarded, with the result that 4,648 papers from 382 organizations were left in the analysis. The authors of the survey draw attention to the limitations of their work, and especially to the deliberate bias towards American authorship and the small interval of time over which the sample was made. Comparison with earlier surveys shows that atomic, molecular and nuclear physics as well as quantum theory are overrepresented and that astrophysies, geophysics and solid state physics are under-represented.

With these limitations, it turns out that ten of the institutions identificd, less than three per cent of the total, published an average of 116 papers each in the period of six months covered by the survey and that, at the other end of the scale, 285 institutions published fewer than three papers each. The laboratories concerned are (with papers published in brackets) the Argonne Nationil Laboratory (192), Bell Telephone Laboratories at Murray Hill (179), Massachusetts Institute of 'Technology (157), Brookhaven National Laboratory (106), Stanford University (101), Cornell University (97), National Bureau of Standards (82.5), University of California at Berkeley (82), Harvard University (82), Lawrence Radiation Laboratory (82).

Among universities (180 were productive enough to be included in the survey), the spread of productivity was as great as for the sample as a whole. At the top, ten university physics laboratories produced an average of $89 \cdot 25$ papers in the half-ycar, while at the opposite extreme, 121 laboratories produced only $3 \cdot 36$ papers in the half-year on the average. The list of universities concerned is the familiar list which crops up in all studies of this kind-the production of graduate students, for example, or the winning of NSF grantsthe Massachusetts Institute of Technology, Stanford University, Cornell University, Harvard University, University of California at Berkeley, Princeton University, Chicago University, Pennsylvania University, University of Illinois and University of California at Los Angeles.

Most probably the survey is least reliable on what it has to say about government laboratories-certainly it is a great surprise that institutions like the Goddard Space Flight Center failed to make the top fourteen. No doubt this is a reflexion of the admitted bias against the astrophysical and geophysical sciences in the survey.

Among industrial laboratories, the division between the high producers and the lower producers seems to be less stark, and there are more laboratories with only middling productivity. The authors of the survey believe that thcir analysis can provide a valuable means of spelling out objectively the research interests of particular companies. The concentration of authors in a few states-California, New York, New Jersey, Massachusetts and Illinois-is well shown up by the survey but is no great surprise.

The research programme on physics information has also provided a view of the distribution of the secondary literature in physics. On the basis of a survey of secondary sources, mostly abstracting journals, the members of the project have discovered that the Soviet Union is the most prolific producer of bibliographic information, producing 116,000 items of bibliographic information a year. English, however, is the principal language-47.8 per cent of all entries in abstracting journals were in English, with Japanese second at 11.6 per cent, French third at 8.8 per cent and Russian equal to German at $7 \cdot 3$ per cent. What the survey has not done so far is to examine the use made of the abstracting services by working physicists.

\section{PEACEFUL EXPLOSIONS}

\section{Plowshare af Las Vegas}

'IHE conference on engineering with nuclear explosives arranged by the American Nuclear Society seems to have covered even more ground than previous occasions of the kind, but it remains to be seen whether it will substantially have advanced the economic case for using nuclear explosives for civilian engineering occupations. The confercnee was attended not merely by engineers from the AEC laboratories and American industries and universities but by representatives from the atomic energy rescarch establishments in Britain and France.

The conference will have provided as admirable opportunity for surveying the effects of nuclear explosions underground, and several laboratories seem to have been engaged on attempts to predict what 
happens mechanically to underground strata when explosions take place. It seems widely to be agreed that the problem is to predict what happens when rocks are exposed to pressures of about a million bars decaying to about a hundred bars in a hundred seconds. Computer programs have been used to estimate the varying effects of different kinds of rock. Much of what happens underground seems to depend on the rate at which the internal pressure in the cavity decays by heat loss into the surrounding rock, itself determined by the conductivity of the materials. Although scaling up the results of small explosions to predict the effects of larger ones is apparently of considerable if limited value, the prediction of chemical processes underground is more difficult.

Chemical uncertainties have a bearing on the problem of vented radioactivity. There seems to be some uncertainty about the ideal behaviour of underground explosions and necessarily about the radioactive consequences of cratering explosions. In one calculation presented at the conference, on the assumption that only ten out of a hundred kilotons of a Plowshare explosion is derived from fission, the hazards from radioactivity involved in building underground structures such as storage reservoirs for natural gas or oil would consist only of radioactive tritium, and there is even a chance that this might be removed by bleaching. Experience with the Gasbuggy underground explosion two years ago, intended to produce a supply of natural gas, seems to have been that radioactive iodine is not a hazard, but that tritium and radioactive krypton are the chief sources of hazard, especially if the gas is distributed (which has not yet been attempted). On the success of the Gasbuggy experiment as an economic enterprise, speakers at the conference estimated that the El Paso Natural Gas Company of Texas will eventually be able to recover 19 per cent of the gas originally in place under the 160 acre site. The fractures produced by the underground explosion seem to extend sufficiently far to promise steady operation of such a well, but the gas withdrawn from the Gasbuggy hole seems to have been diluted to half its volume by a mixture of carbon dioxide and hydrogen produced, it is assumed, in the explosion. In the past two years, however, the hydrocarbon content of the gas has increased to 90 per cent as the original products have been swept to the surface.

The use of nuclear explosions for mining ores has been tested by a number of explosions in the past few years, but it seems that much depends on whether ore bodies are correctly placed with respect to the surface for the technique to be usable. The release of oil from oil shale was also described at the conference, as was the production of relatively large amounts of heavy nuclides by the exposure of uranium and thorium targets to the neutron flux of an underground explosion-it now seems probable that the Hutch underground explosion will have produced in this way 10,000 million atoms of fermium-257-a hundred times as much as previously obtained. For the most part, however, interest still centres on excavation schemes such as the Panama Canal and the scheme called Project Carryall intended to drive a combined railway and road through the western desert of the United States. One new candidate at the conference was a proposal to drive a canal from the Mediterranean through the Gulf of Gabes in Tunisia to the large tract of land in Algeria and Tunisia that lies below sea level.
Potential benefits are said to include a seaway to help with removing oil and minerals, a tourist trade and even climatic change. It is calculated by a group from the Georgia Institute of Technology that the whole project could be mounted for $\$ 710$ million spread over seven years.

\section{SCIENCE POLICY Harvard Program Soldiers on}

The Program on Technology and Society at Harvard University seems to have followed its own advice, made public a year ago, by paying more attention to the relationship between technology and what is called "the life of the individual". This is the chief interest of the annual report for 1968-69, now published. The research programme has been supplemented by projects intended to examine the effects of technological change on work and leisure, and the staff has also begun on a long-term inquiry into the psychological adaptability of people at work. The Program continues to occupy itself with its unique blend of sociology and technology.

The study of the relationship between work and leisure, the responsibility of Harold L. Wilensky, professor of sociology at Berkeley, has been based on a survey among 1,354 men in jobs as different as university professors and manual workers. The sample has been deliberately biased so as to include within each category of workers the most and the least progressive kinds of jobs. The hope is that an analysis of this population will suggest how people in different kinds of jobs choose between income and leisure. Professor Wilensky has established that television plays a dominating part in the use made of leisure time, and he has now resolved to concentrate on "the quality of the television experience". Briefly, he seems to have found that men with boring jobs spend what leisure they have looking at the television screens, however bad the material to be seen, but that men with more intellectually demanding jobs spend their leisure in more interesting ways as well.

The other new project, still at the planning stage, is being organized by Dr Michael Maccoby, from the Institute of Policy Studies in Washington, DC. $\mathrm{He}$ intends to begin with a careful study of a chosen company. The first objective will be an attempt to define the psychological attributes demanded by different kinds of industrial work. The long-term goal is to understand which kinds of people are successful at their jobs and to find out which intellectual abilities are stimulated by particular jobs. Dr Maccoby starts his work with a few preconceptions, among which is the suspicion that the kinds of intellectual skills best suited to success in modern industry may be different from "the abstract intelligence currently dominant in our society and reflected by standard IQ tests".

Among the continuing work of the Program on Technology and Society is a scheme for examining the extent to which the arrival of computers will affect the working of public authorities. Professor Alan F. Westin, from Columbia University, is among other things concerned with the classical Big Brother question of whether the storage of large amounts of information in publicly used computers will eventually lead to situations in which legislation and the conduct of daily operations in public authorities are tailored so as to suit the convenience of the computer programmers. 